\title{
The influence of quasi resonant internal waves on the radar imaging mechanism of shallow sea bottom topography
}

\section{Influence des ondes internes quasi-résonantes sur les images radar de la topographie d'un fond marin peu profond}

\author{
Ingo Hennings ${ }^{a}, *$, Margitta Metzner ${ }^{a}$, G.-P. de Loor ${ }^{b}$ \\ ${ }^{\mathrm{a}}$ GEOMAR, Forschungszentrum für marine Geowissenschaften der, Christian-Albrechts-Universität zu Kiel, Wischhofstrasse 1-3, 24148 Kiel, Germany \\ ${ }^{\mathrm{b}}$ Benoordenhoutseweg 277, NL-2596 BJ Den Haag, The Netherlands
}

Received 10 May 2001; received in revised form 10 December 2001; accepted 18 February 2002

\begin{abstract}
During previous field experiments in the North Sea it was often assumed that the water column in such shallow coastal tidal waters is vertically well mixed and stratification was neglected when discussing the Normalized Radar Cross Section modulation caused by the sea floor. In this paper the influence of quasi resonant internal waves with the sea bed on the radar imaging mechanism of submarine sand waves itself is investigated. In situ data of the tidal current velocity and several water quality parameters such as sea surface temperature, fluorescence, and beam transmittance were measured in the Southern Bight of the North Sea in April 1991. Simulations of the total NRCS modulation caused by sand waves and internal waves as a function of the current gradient or strain rate induced by the internal wave current field at the sea surface have been carried out using the quasi-steady approximation and linear internal wave theory. As a first approximation the strain rate depending on stratification was calculated using the two-layer model. These simulations demonstrate that at least a density difference between the two layers of the order of $\Delta \varrho \approx 1 \mathrm{~kg} \mathrm{~m}^{-3}$ is necessary for a sinusoidal thermocline to effect the total NRCS modulation considerably. The NRCS modulation as a function of wind friction velocity has been calculated independently and is discussed with regard to the strain rate of the surface current field caused by the superimposed imaging mechanisms of sand waves and internal waves. It turned out that the existence of a surface roughness-wind stress feedback mechanism cannot be excluded. (C) 2002 Ifremer/CNRS/IRD/Éditions scientifiques et médicales Elsevier SAS. All rights reserved.
\end{abstract}

\section{Résumé}

Précédemment, en mer du Nord, la stratification, pratiquement inexistante dans cette région peu profonde et à fortes marées, a été négligée lors de la discussion de la modulation par le fond marin de la section efficace normalisée du radar. Dans le présent article, nous examinons l'influence des vagues internes quasi-résonantes et du fond sous-marin sur les images radar du fond sableux. Les données in situ ont été recueillies en avril 1991 dans la partie sud de la mer du Nord : vitesse du courant de marée, température de surface, fluorescence et transmission. Des simulations de la modulation de la section efficace normalisée du radar produite par les ondulations du fond sableux et les ondes internes en fonction du gradient de courant ou de la tension induits par le champ de courants des ondes internes à la surface de mer ont été réalisées. L'approximation quasi-stationnaire et la théorie linéaire des vagues internes ont été utilisées. En première approximation, la tension dépendant de la stratification a été calculée en utilisant un modèle à deux couches. Ces simulations montrent une différence de densité entre les deux couches d'au moins $\Delta \varrho \approx 1 \mathrm{~kg} \mathrm{~m}^{-3}$ est nécessaire pour une thermocline sinusoïdale pour modifier fortement la section efficace normalisée du radar. Cette modulation, fonction de la vitesse de friction du vent, a été calculée séparément et

\footnotetext{
* Corresponding author.

E-mail addresses: ihennings@geomar.de (I. Hennings), gpdeloor@wxs.nl (G.P. de Loor).
} 
est discutée en fonction de la tension du champ de courant superficiel produit par les images superposées des ondulations du sable et des ondes internes. L'existence d'un mécanisme de rétroaction de tension du vent ne peut pas être exclue. (C) 2002 Ifremer/CNRS/IRD/Éditions scientifiques et médicales Elsevier SAS. Tous droits réservés.

Keywords: Radar imaging mechanism; Sea bottom topography; Stratification; Internal wave; Strain rate

Mots clés: Mécanisme des images radar; Topographie des fond marins; Stratification; Ondes internes

\section{Introduction}

Airborne Synthetic Aperture Radar (SAR) images taken along the continental shelf off Cape Hatteras, North Carolina, showed superimposed sea surface signatures caused by internal waves and submarine sand waves Li_et al, 1999). In the open ocean, coastal seas and estuaries internal waves of different size and/or type are commonly generated by the flow of water over sea bottom topography Munk 1981. Kranenhurg, 1988a; 1988h; New and Dyer, 1988). However, the stratification of the vertical water column can be either created continuously, e.g. as a continuous density profile, or as a two-layer system with two different densities where so called interfacial waves can be developed. Internal waves extract energy from the mean (tidal) flow and may travel either upstream or downstream or can be in resonance with the wavelength of the topographic forcing. It was shown by New and Dyer (1988) that in the Tees estuary, United Kingdom, short internal waves of 10-12 m wavelength were generated during flood tidal phase by mega ripples at the sea floor of similar length scales. An echosounder record from La Chapelle Bank off the west coast of France, at the continental shelf edge, showed internal waves revealed by a well-developed scattering layer existing of particles in the water overlying sand waves of similar extension Stride and Tucker. 1960. Field observations made by Pietrzak et al. (1990) of stratified fluid over a nearly periodic topographic relief presented a unique series of resonant internal waves. These observations illustrate the presence of internal waves with wavelengths comparable with those of the sea bed topography. The amplitudes of the internal waves were three to four times larger than the heights of the topography generating them. Resonant internal waves are important for the understanding of flow dynamics of stratified coastal environments if radar imagery will be used for retrieving water depths.

Signatures of Normalized Radar Cross Section (NRCS) modulations at the ocean surface due to internal waves and sea bottom topography are visible on a variety of radar images derived by shore- and ship-based radar as well as by Real Aperture Radar (RAR) on board air- and spaceborne platforms. The radar imaging mechanism of internal waves and sea bottom topography are satisfactory explained in the literature. The theory of radar imaging of internal waves was published by Alpers (1985). Thompson and Gasparovic 1986) and Holliday et al.(1987). Kropfli et al. (1999) showed relationships between strong internal waves in the coastal zone and their associated radar and radiometric signatures. Theoretical models for the radar imaging mechanism of sea bottom topography were described by Alpers and Hennings (1984). Shuchman et al. (1985). Hennings (1990), Romeiser and Alpers (1997) and Vogelzang (1997). It was shown by Li_et_al_(1999) that radar signatures of internal waves are superimposed on surface manifestations directly caused by the sea bed. The study of radar signatures in coastal waters described by Donato et al. (1997) also demonstrated the critical nature that topographic and stratified effects could have via the associated hydrodynamics for the interpretation of radar imagery. It is not easy under such condition to employ radar remote sensing techniques for a cost-effective retrieval of water depth information from radar images. Other phenomena like frontal boundaries, small scale eddies, slicks, oil spills, patches of turbulence and ship wakes are quite common in coastal waters and can disturb as well the radar signatures of the sea bed.

The theory and a schematic sketch of the influence of internal waves on the radar imaging mechanism of the sea bed are presented in section 2. A brief summary of the physical interpretation of resonance between sea bottom topography and internal waves is given in the same section. In situ measurements of the tidal current velocity and several water quality parameters carried out in the Southern Bight of the North Sea supporting the theoretical considerations are reported in section 3. Calculations of the Normalized Radar Cross Section (NRCS) modulation as a function of strain rate at different conditions of stratification using the two-layer model as a first approximation are presented in section 4.1. Investigations of the resonance condition between sand waves and internal waves using in situ data are carried out in section 4.2. Independent calculations of the NRCS modulation as the function of wind friction velocity are shown in section 4.3. Finally, section 5 contains the discussion and conclusions.

\section{Theory}

In this paper, only the weak hydrodynamic interaction theory in the relaxation time approximation is used for describing the interaction of the surface waves with a variable current LAlpers and Hasselmann, 1978. For the NRCS modulation $\left(\Delta \sigma / \sigma_{0}\right)_{\text {top }}$ Alpers and_Hennings (1984 
have developed an approximate theory which has the principal relation:

$$
\left(\frac{\Delta \sigma(\underline{x})}{\sigma_{0}}\right)_{\text {top }}=-\frac{4+\gamma}{\mu} \frac{\partial U_{x}(\underline{x})}{\partial x}
$$

where $\Delta \sigma(x)=\sigma(\underline{x})-\sigma_{0}$ is the local change in radar scattering cross section, $\sigma_{0}$ is the constant background NRCS corresponding to areas where the variable surface current is zero, $x=(x, y)$ is the space variable, $\gamma=0.5$ for gravity waves and $\gamma=1.5$ for capillary waves, respectively, $\mu$ is the relaxation rate, $U_{x}(\underline{x})$ is the component of the surface current velocity associated with the sea bottom topography, and $x$ is the projection of the antenna axis on the horizontal plane.

Here, this model is restricted to the surface current velocity component $U_{\text {perp }}$ perpendicular to the sand wave crest. Thus equation (1) reads:

$$
\left(\frac{\Delta \sigma(\underline{x})}{\sigma_{0}}\right)_{\text {top }}=-\frac{4+\gamma}{\mu} \cos ^{2} \phi \frac{\partial U_{\text {perp }}}{\partial x_{\text {perp }}}
$$

where $\phi$ denotes the angle between the $x$ and $x_{\text {perp }}$ direction normal to the sand wave crest.

The surface current velocity component $U_{\text {perp }}$ of equation (2) is approximated as a sawtooth profile caused by asymmetric sand waves and is defined as:

$$
U_{\text {perp }}=U_{0}+\frac{\Delta U_{\text {perp }} x_{\text {perp }}}{L_{\mathrm{SSL}}},-L_{\mathrm{SSL}} \leqslant x_{\text {perp }} \leqslant 0
$$

and

$$
U_{\text {perp }}=U_{0}+\frac{\Delta U_{\text {perp }} x_{\text {perp }}}{L_{\mathrm{GSL}}}, 0 \mathrm{~m} \leqslant x_{\text {perp }} \leqslant L_{\mathrm{GSL}}
$$

where $U_{0}$ is the constant equilibrium surface current velocity, $\Delta U_{\text {perp }}$ is the maximum surface current velocity variation caused by the sand wave profile, $L_{\mathrm{SSL}}$ is the length scale of the steep slope of the sand wave, and $L_{\mathrm{GSL}}$ is the length scale of the gentle slope of the sand wave, respectively.

According to Alpers (1985) equations (1)-(2) are also valid for the NRCS modulation of internal waves $\left(\Delta \sigma / \sigma_{0}\right)_{\text {int }}$, where $\phi$ denotes the angle between the $x$ and $x_{\text {perp }}$ direction as in equation (2), but where $x_{\text {perp }}$ is defined as the direction normal to the internal wave crest.

The current velocity component $U_{\text {perp }}$ perpendicular to the crest of the internal wave induced at the water surface by the internal wave can be expressed according to Bhillips 1977 as:

$$
\begin{aligned}
U_{\text {perp }}=-\eta_{0} n\left(\sinh \left(K_{\text {perp }} d\right)\right)^{-1} & \exp \left[i\left(K_{\text {perp }} x_{\text {perp }}-n t\right)\right]
\end{aligned}
$$

where $t$ is the time variable, $\eta_{0}$ is the amplitude of the internal wave, $n$ is the radian frequency of the internal wave,
$K_{\text {perp }}$ is the wave number of the internal wave in $x_{\text {perp }}$ direction, $\mathrm{d}$ is the mean thermocline depth, and $\mathrm{i}$ is the imaginary unit. The first-order solution of equation (4) is valid for the lowest internal wave mode. A more detailed description is given by Phillips (1977).

Derivating equation (4) and making a quasi-steady-state approximation yields the surface strain rate $(z=0$, with $z$ the vertical space variable) as follows:

$$
\begin{aligned}
& \frac{\partial U_{\text {perp }}}{\partial x_{\text {perp }}}=-i K_{\text {perp }} \eta_{0} n\left[\sinh \left(K_{\text {perp }} d\right)\right]^{-1} \\
& \exp \left(i K_{\text {perp }} x_{\text {perp }}\right)
\end{aligned}
$$

A quasi-steady-state approximation was used because the time variations considered here occur on a scale much less than the period of the semi-diurnal tide. To investigate only such internal waves that show a clear relationship with the sea bottom topography suggest that the resonance condition can be isolated using a simple steady-state linear model. The conditions shown in Fig. 1 are correct if the resonant internal wave propagates from left to right. One might also think of stationary internal waves travelling in opposite direction to the tidal current, enhancing the sea bottom topography effect at the surface, rather than decreasing it (regions of divergence and convergence in Fig. 1b will be reversed then). On the other hand one can think of a standing internal wave (in a fluid with constant density gradient) rather than a travelling internal wave (Pietrzak et al. 1990) This will shift the convergence or divergence regions at the surface by a quarter internal wavelength Defant. 1960.

Here, the applicability of a two-layer model for stratification will be considered. Such a model can only describe the first internal mode. But in the real fluid it may well be possible that additional modes are important.

The radian frequency relation developed from the dispersion equation for the first mode of the internal wave according to Ehillips (1977) reads:

$$
\begin{aligned}
n^{2}=g K_{\text {perp }}\left(\frac{\Delta \varrho}{\varrho}\right)\left[K_{\text {perp }} \varepsilon\right. & +\operatorname{coth}\left(K_{\text {perp }} d\right) \\
& \left.+\operatorname{coth}\left(K_{\text {perp }}(D-d)\right)\right]^{-1}
\end{aligned}
$$

where $g$ is the acceleration of gravity, $Q$ is the mean water density, $\Delta \varrho=\varrho_{2}-\varrho_{1}$ is the density difference between the upper and lower water layers, $\varepsilon$ is the thickness of the pycnocline, and $D$ is the water depth.

If $K_{x} \varepsilon<<1$ or if the thickness of a pycnocline is much smaller than the horizontal wavelength of the internal wave, then equation (6) reduces to:

$$
\begin{aligned}
n^{2}=g K_{\text {perp }}\left(\frac{\Delta \varrho}{\varrho}\right)[\operatorname{coth}( & \left.K_{\text {perp }} d\right) \\
& \left.+\operatorname{coth}\left(K_{\text {perp }}(D-d)\right)\right]^{-1}
\end{aligned}
$$




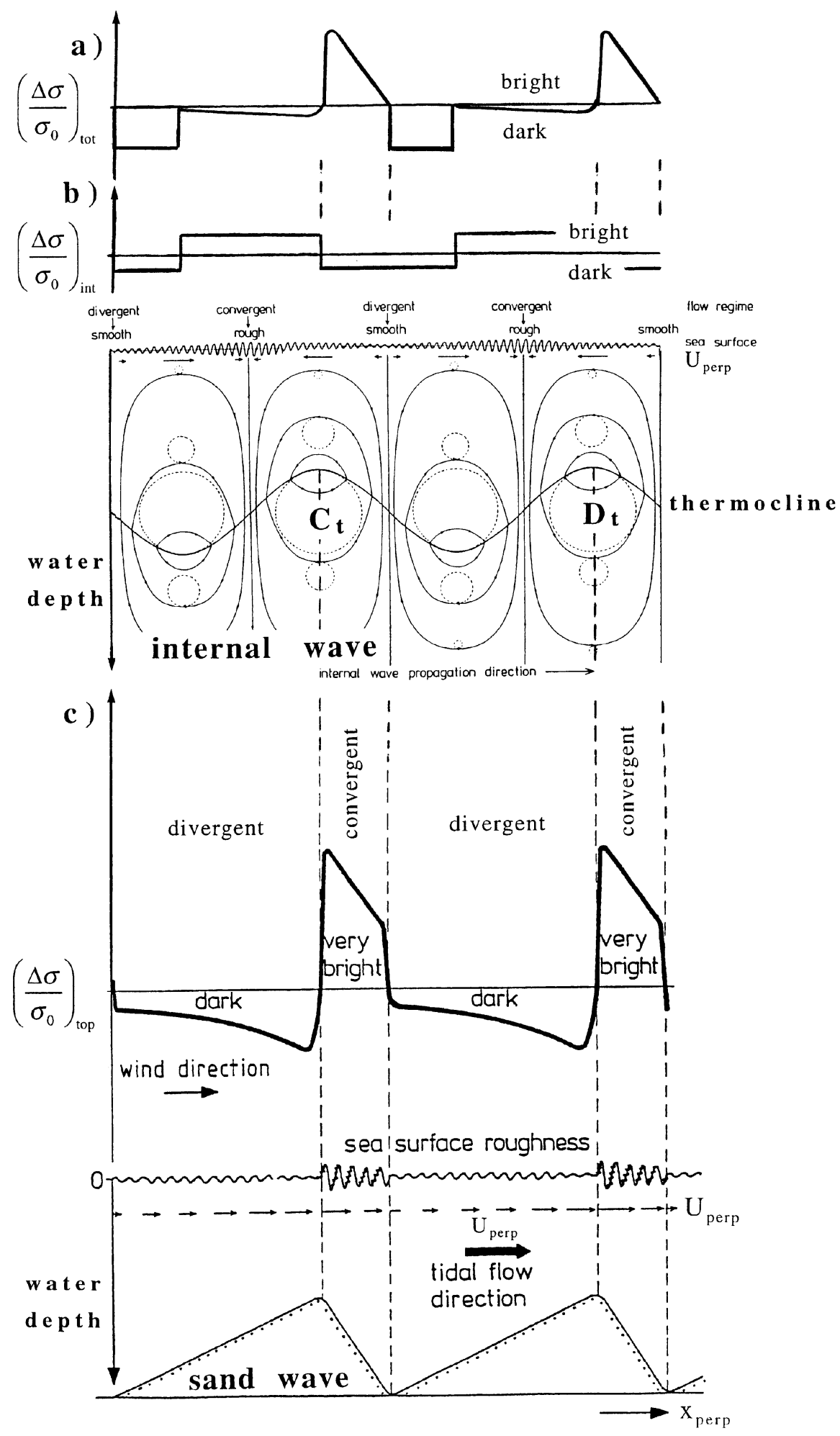

Fig. 1. Schematic visualization of a) the total NRCS modulation $\left(\Delta \sigma / \sigma_{0}\right)_{\text {tot }}$ due to the NRCS modulation $\left(\Delta \sigma / \sigma_{0}\right)_{\text {int }}$ of internal waves and due to the NRCS modulation $\left(\Delta \sigma / \sigma_{0}\right)_{\text {top }}$ of sea bottom topography for the special case that the conditions for resonance are satisfied if the free internal wavelength coincides with the wavelength of the topographic forcing; b) Streamlines and particle velocities associated with linear sinusoidal internal waves which are in resonance with the sand waves along the thermocline; that part of the internal wave is marked by $C_{\mathrm{t}}$ and $D_{\mathrm{t}}$ where calculations of $\left(\Delta \sigma / \sigma_{0}\right)_{\text {tot }},\left(\Delta \sigma / \sigma_{0}\right)_{\text {int }}$, and $\left(\Delta \sigma / \sigma_{0}\right)_{\text {top }}$ have been performed (see Fig. 8); c) Relationship between an asymmetric sand wave profile and variations in tidal current velocity, short-scale surface roughness, and $\left(\Delta \sigma / \sigma_{0}\right)_{\text {top }}$. The steep slopes of the sand waves are located downstream from the sand wave crests and are associated with strongly enhanced values of $\left(\Delta \sigma / \sigma_{0}\right)_{\text {top }}$ (bright streaks). It is shown as a first approximation that the enhanced and reduced roughness modulations at the sea surface caused by the internal waves are more or less spatially in antiphase with the roughness modulations due to the sand waves itself (modified after Defant (1960) and Alpers and Hennings (1984). 
The regions of maximum convergence $\left(-\partial U_{\text {perp }} / \partial x_{\text {perp }}\right)$ and divergence ( $\left.\partial U_{\text {perp }} / \partial x_{\text {perp }}\right)$ derived from equation (5) are positioned above the nodes of the displacement of the thermocline (see Fig. 1).

Finally, the total NRCS modulation is then given by the sum of the NRCS modulation due to the sea bottom topography and internal wave as:

$$
\left(\frac{\Delta \sigma}{\sigma_{0}}\right)_{\mathrm{tot}}=\left(\frac{\Delta \sigma}{\sigma_{0}}\right)_{\mathrm{top}}+\left(\frac{\Delta \sigma}{\sigma_{0}}\right)_{\mathrm{int}}
$$

Fig. 1 shows a schematic presentation of the total NRCS modulation $\left(\Delta \sigma / \sigma_{0}\right)_{\text {tot }}$ (Fig. 1a) due to the influence of a sinusoidal internal wave (Fig. 1b) on the radar imaging mechanism of asymmetric sand waves (Fig. 1c) for the special case that the conditions for resonance between the sea bed and the internal wave are satisfied. As a first approximation the thermocline was assumed here as a sinusoidal type (Fig. 1b). However, this can be an oversimplification because the thermocline can deviate from a sinusoidal type as shown in Fig. 7c. The positions of maximum strain rates $\left(\partial U_{\text {perp }} / \partial x_{\text {perp }}\right)_{\max }$ and minimum strain rates $\left(-\partial U_{\text {perp }} / \partial x_{\text {perp }}\right)_{\min }$ due to direct hydrodynamic modulation caused by sinusoidal sand waves and induced also by a sinusoidal thermocline of the internal wave are spatially in antiphase if the special case of resonance is fulfilled. This implies that enhanced or reduced water surface roughness patterns of the internal wave are associated with reduced or enhanced roughness patterns caused by the sand waves itself. The total NRCS modulation $\left(\Delta \sigma / \sigma_{0}\right)_{\text {tot }}$ is expected to be low if both strain rates are of the same order of magnitude. This behavior changes if the sand waves are of asymmetric type because this implies also an asymmetric variation in $\left(\Delta \sigma / \sigma_{0}\right)_{\text {top }}$. Fig. 1a shows that the total NRCS modulation $\left(\Delta \sigma / \sigma_{0}\right)_{\text {tot }}$ is enhanced above the steep slope of the sand wave due to its direct modulation effect $\left(\Delta \sigma / \sigma_{0}\right)_{\text {top }}$. At the trough of the sand wave there is an area where $\left(\Delta \sigma / \sigma_{0}\right)_{\text {tot }}$ can also be significantly reduced at the sea surface (see Fig. 1a). This is caused by the superposition of both the reduced $\left(\Delta \sigma / \sigma_{0}\right)_{\text {top }}$ due to the effect of the sand wave itself as well as the reduced modulation effect $\left(\Delta \sigma / \sigma_{0}\right)_{\text {int }}$ of the divergent current field associated with the internal wave. At these positions also reduced NRCS modulations as a function of wind friction velocity (see section 4.3) can be expected due to the existence of a surface roughness-wind stress feedback mechanism Romeiser et al.. 1999)

A physical interpretation of resonance between sea bottom topography (sand waves) and internal waves was given by Bietrzak et al_(1990). They used the quasi-steady approximation and linear internal-wave theory assuming a steady, non rotating, inviscid fluid, taking into account a continuous density profile and using a constant density gradient for analytical demonstration. Furthermore, they show that the conditions for resonance are realized if the free internal wave number $K_{\text {perp }}$ that satisfies the unforced equations coincides with the wave number of the topographic forcing and can be expressed as:

$$
K_{\text {perp }}(z)=\left[l^{2}(z)-m^{2} \pi^{2} D^{-2}\right]^{1 / 2}
$$

where $l^{2}(z)$ is defined by:

$$
l^{2}(z)=\frac{N^{2}(z)}{U^{2}}-\frac{1}{U} \frac{\partial^{2} U}{\partial z^{2}}
$$

with $U=U(z)$ the depth dependent current velocity and $N(z)$ the buoyancy or Brunt-Väisälä frequency:

$$
N^{2}(z)=-\frac{g \partial \varrho}{\rho \partial z}
$$

with $m=0,1,2, \ldots$.

\section{Material and methods}

During the field experiment on 15-26 April, 1991 of the "Mapping of Sea Bottom Topography in a Multi Sensor Approach" project oceanographic and meteorological data have been collected at the Measuring Platform Noordwijk (MPN) and on board of three research vessels off the Dutch coast in the southern North Sea (for location see Fig. 2b). The aim of this project was to study the relation between radar and optical (sunglint) signatures associated with submarine sand waves Vogelzang. 1993: Hennings et al. 1994: Matthews et al. 1997) The in situ data described here concentrate on the measurements carried out on board $R V$ Prince Madog operated by the School of Ocean Sciences, Menai Bridge, Wales, United Kingdom. The position of the research vessel was determined by a Differential Global Positioning System (DGPS) device with an accuracy of about $2-5 \mathrm{~m}$.

\subsection{Bathymetric data}

A map of the sea bottom topography of the whole study area off the Dutch coast in the southern North Sea is shown in Fig. 2a. The bathymetric surveys have been carried out by $R V$ Christiaan Brunings with multibeam echosounders after the experiment in summer 1991. About $64 \%$ of the data have been recorded with a STN Atlas marine electronics FANSWEEP 10 system and 36\% with a Simrad EM 100 system. All data are based on a spatial resolution of $5 \times 5 \mathrm{~m}$. The study area is a square of $9.8 \times 9.8 \mathrm{~km}$. Sand waves with a height of 2-6 m and a crest to crest distance of typically $500 \mathrm{~m}$ are dominant bedforms at the sea floor. The water depth varies between $16.95 \mathrm{~m}$ and $28.15 \mathrm{~m}$. Crests of sand waves are generally oriented perpendicular to the dominant tidal current direction. The drift track of $R V$ Prince Madog on April 24, 1991 between 11:40 UTC and 13:40 UTC is indicated by A-B in Fig. 2a. The two black arrows represent the current direction $U$ and wind direction $U_{\mathrm{w}}$, respectively, 


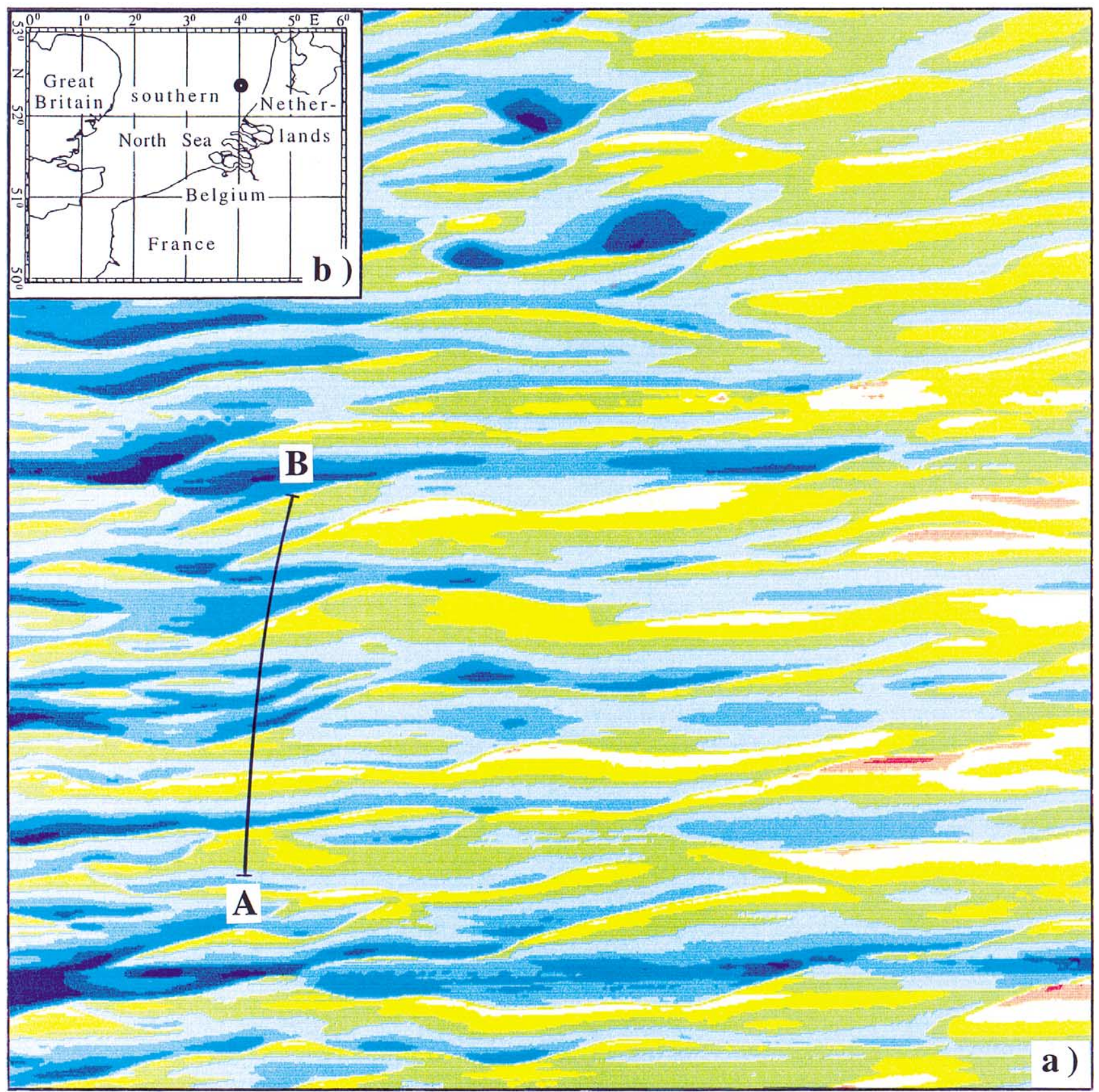

Depths in meters

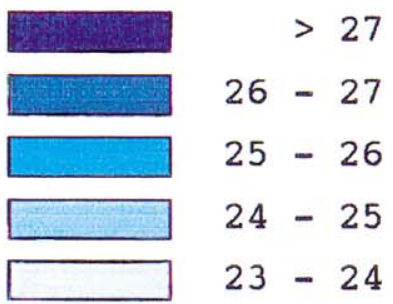

\section{$1 \mathrm{~km}$}

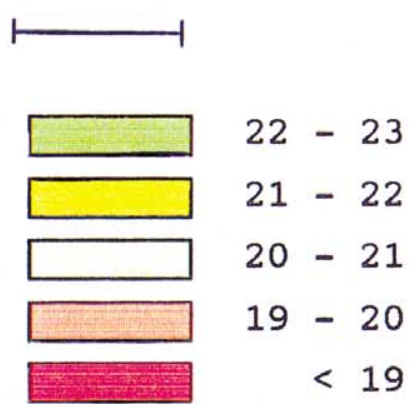

Fig. 2a. Bathymetric map of the study area (location is indicated by a circle in the inset of Fig. 2b) off the Dutch coast in the southern North Sea with the track A-B of RV Prince Madog drifting during flood current phase from southwest to northeast between 11:40 UTC and 13:40 UTC on April 24, 1991. The study area has a size of $9.8 \times 9.8 \mathrm{~km}$. The position of the lower left corner is at $52.361410^{\circ} \mathrm{N}$ and $3.931553^{\circ} \mathrm{E}$. The $x$-axis of the map is directed to $121^{\circ}$ true north. Current direction $U$ and wind direction $U_{\mathrm{w}}$ are shown by black arrows. 
at 11:51 UTC. Low wind speeds of $2-4 \mathrm{~m} \mathrm{~s}^{-1}$ from southern directions have been measured during the drift.

\subsection{CTD and AVHRR SST data}

Conductivity-Temperature-Depth (CTD) data measured by a Neil-Brown CTD probe on board $R V$ Prince Madog are presented in Fig. 3a-b. These data have been sampled on April 24, 1991 at 12:55 UTC and at 18:15 UTC, respectively. Both vertical profiles of the CTD probe show a developing two layer system. Fig. 3a shows a water temperature profile with a beginning thermal stratification of the water column. A fairly well defined thermocline at approximately $500 \mathrm{hPa}$ corresponding to a water depth of $D=d=5 \mathrm{~m}$ is presented in Fig. $3 \mathrm{~b}$ with a temperature jump of about $0.5^{\circ} \mathrm{C}$. The upper layer had a density of $\varrho_{1}=1026.38 \mathrm{~kg} \mathrm{~m}^{-3}$ (density $\varrho=\sigma_{\theta}+1000 \mathrm{~kg} \mathrm{~m}^{-3}$, where $\sigma_{\theta}$ is the potential density). The uniform lower layer had a thickness of $d_{2}=D-d=21 \mathrm{~m}-5 \mathrm{~m}=16 \mathrm{~m}$ where $D$ is the mean water depth at this position with a density of $\varrho_{2}=1026.45 \mathrm{~kg} \mathrm{~m}^{-3}$. Here the mean density is defined by $\varrho=\left(\varrho_{1}+\varrho_{2}\right) 2^{-1}$ and the density difference between the two layers is $\Delta \varrho=\varrho_{2}-\varrho_{1}$. The equivalent two-layer distribution, constructed with the above-mentioned criteria is shown as well in Fig. $3 b$ by dashed lines. The temperature variations shown in Fig. $3 \mathrm{~b}$ are consistent with the notion of colder water being brought to the surface by sand waveinduced flow perturbations because the temperature changes shown in Fig. 7c recorded on board RV Prince Madog at the water depth of $3 \mathrm{~m}$ are of the same order of magnitude. The salinity profile also had changed during both acquisition times. An increasing salinity profile from the surface to the bottom is shown in Fig. 3a, while a nearly homogeneous salinity distribution of $34 \mathrm{PSU}$ is present at 18:15 UTC as shown in Fig. 3b. This lower salinity distribution is caused by merging of lower salinity of the Rhine water discharge. The creation of a rather homogeneous distribution without any stratification could be due to low evaporation without enhancement of salinity values at the surface.

The reason why a significant vertical thermal stratification had developed on this day in addition to the existing daily cycle stimulated by the solar radiation can be revealed by the sea surface temperature (SST) distribution of the southern North Sea taken by the Advanced Very High Resolution Radiometer (AVHRR) on board the NOAA-11 satellite on April 24, 1991 at 13:59 UTC shown in Fig. 4. The AVHRR image shows plumes of warm water with a temperature of $8.5-9{ }^{\circ} \mathrm{C}$ along the Dutch coast originating from the river Rhine which are advected by the predominating tidal current to the northeast covering also the study area. Adjacent SSTs in relation to SSTs of the plumes are generally one degree colder. The Rhine plume influences the local water quality in this region through its far field stratified zone (Van_Alphen et al. 1988) Patches of warm Rhine plume water are periodically detached and decay as

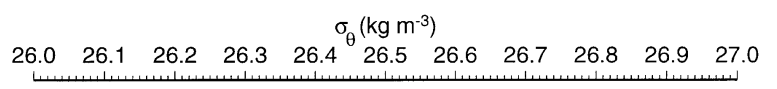

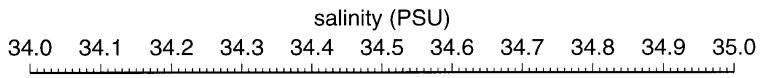
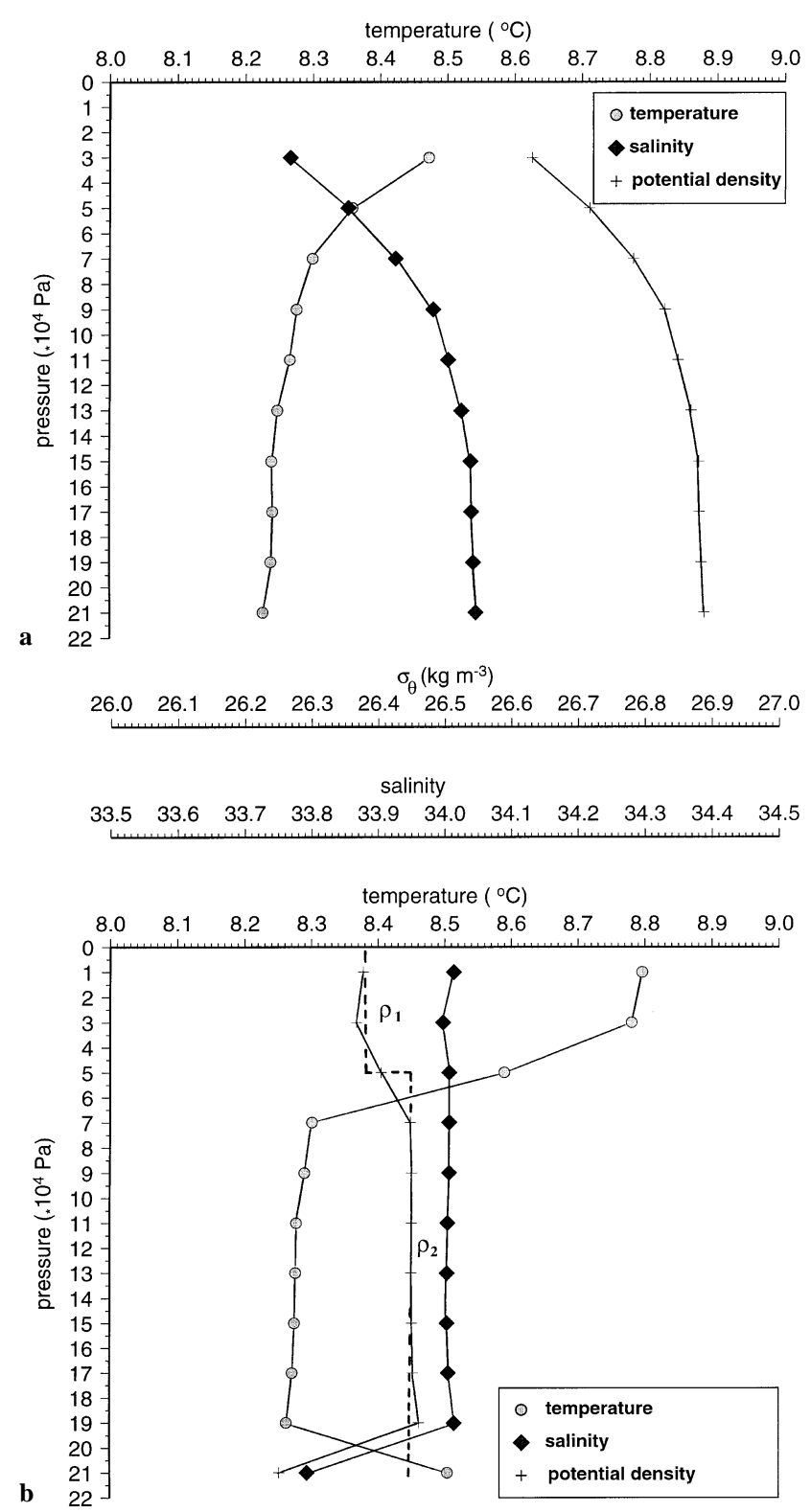

Fig. 3. Conductivity-temperature-depth data from April 24, 1991. The data have been measured at a) 12:55 UTC and b) at 18:15 UTC, respectively. The equivalent two-layer system is indicated by dashed lines in Fig. 3b.

they drift to the northeast with the mean residual flow (see Fig. 4).

\subsection{ADCP and vertical current profile data}

The RV Prince Madog was equipped with a hull-mounted Acoustic Doppler Current Profiler (ADCP) for measuring current speed and direction within the water column. This instrument operated at a transmitting frequency of $300 \mathrm{kHz}$, 


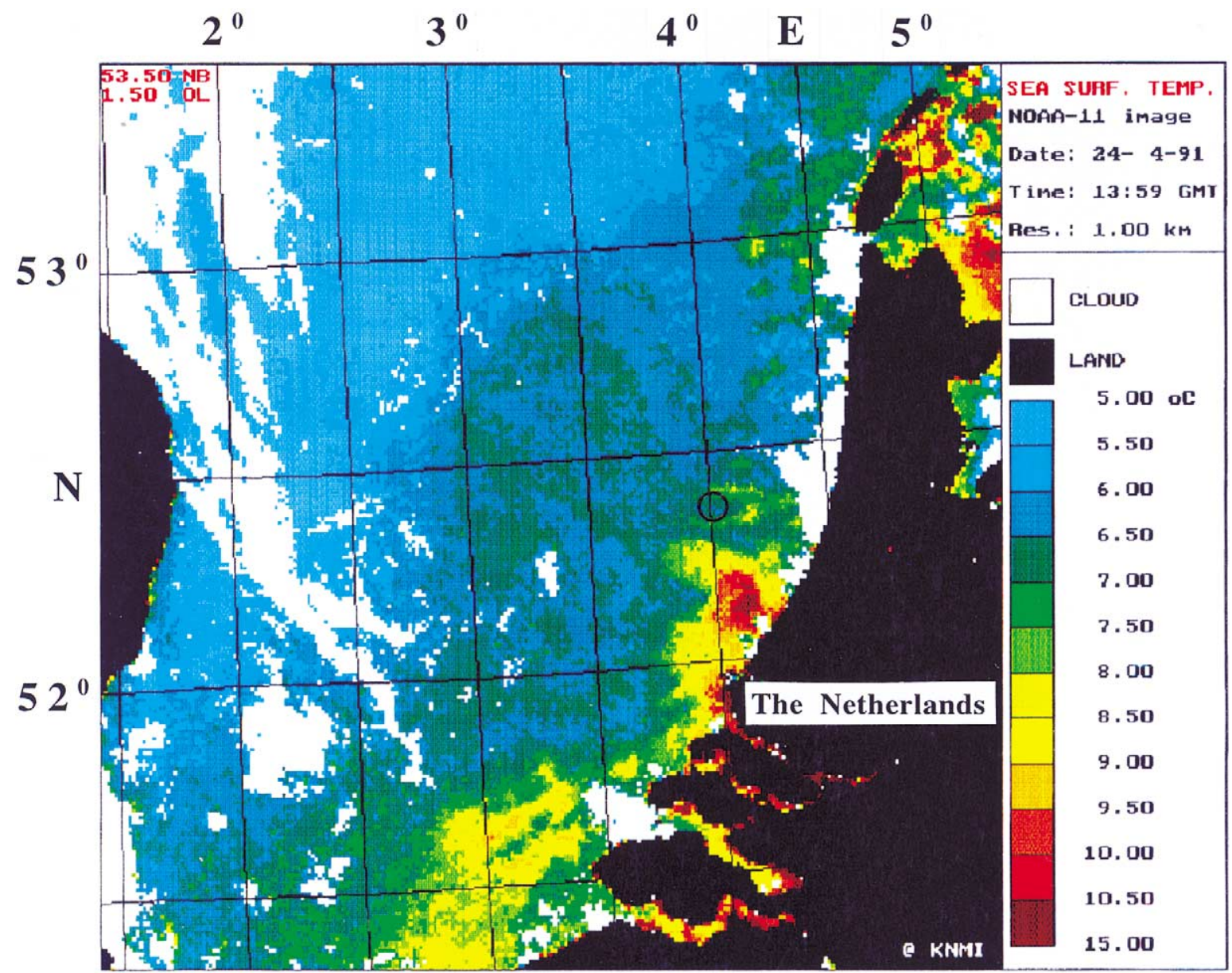

Fig. 4. Sea surface temperature distribution of the southern North Sea taken by the Advanced Very High Resolution Radiometer (AVHRR) on board the NOAA-11 satellite on April 24, 1991 at 13:59 UTC. The study area is indicated by a circle.

depth intervals (bins) of $2 \mathrm{~m}$, and with a sampling interval of $60 \mathrm{~s}$. Only those bins have been considered which covered the depth range between $6 \mathrm{~m}$ and about $85 \%$ of the total water depth. The reason is due to existing disturbances at the transducer depth and due to the sea bottom reflection of the main side lobes of the ADCP which obscures the echos from the water volume. The analysis is concentrated on the drift path during flood current phase indicated by A-B in Fig. 2a.

The parallel $U_{\mathrm{par}}$ and perpendicular $U_{\text {perp }}$ current components relative to the sand wave crests of bin 7 (corresponding to 6-8 $\mathrm{m}$ water depth) as well as the depth averaged perpendicular current velocity component $U_{\text {perp aver }}$ relative to the sand wave crests in relation to the water depth are shown in Figs. 5a-d. In addition, positions of reduced NRCS modulations as a function of wind friction velocity $u_{*}$ (see section 4.3 ) are indicated by horizontal lines between 11:41 UTC and 12:29 UTC. A mean current of the parallel component of $U_{\text {par }}=0.35 \mathrm{~m} \mathrm{~s}^{-1}$ and of the perpendicular component of $U_{\text {perp }}=0.62 \mathrm{~m} \mathrm{~s}^{-1}$ have been calculated from the ADCP data between 11:41 UTC and 12:29 UTC.

The first three sand waves S1-S3 with crests at about 11:48 UTC, 12:06 UTC, and 12:16 UTC cause significant changes in the near-surface current flow of the order of $0.05 \mathrm{~m} \mathrm{~s}^{-1}$ in the parallel and $0.1 \mathrm{~m} \mathrm{~s}^{-1}$ in the perpendicular current component, respectively. In the first two cases, the speed maximizes at or near the sand wave crest, whereas close to 12:22 UTC the maximum speed is downstream near the trough between sand waves S3 and S4. The current field is influenced by a frontal boundary at this position (see also section 3.2) which passed the ship at about 12:15 UTC Matthews et al_ 1997. However, the current seems not to be affected by the two smaller sand waves with crests at about 12:26 UTC and 12:34 UTC.

A mean current velocity of $U_{\text {perp aver }}=0.51 \mathrm{~m} \mathrm{~s}^{-1}$ between 11:41 UTC and 12:29 UTC was calculated from the ADCP data (see Fig. 5c). All sand waves cause significant current changes between $0.05 \mathrm{~m} \mathrm{~s}^{-1}$ and $0.15 \mathrm{~m} \mathrm{~s}^{-1}$ during this time interval. Maximum current velocities have been measured at the crests and minimum current velocities at the troughs of the sand waves. The quantitative evaluation of the agreement between $U_{\text {perp aver }}$ and the water depth $D$ between 11:41 UTC and 12:29 UTC is given in terms of the linear correlation coefficient $r=-0.25$. The corresponding result between $U_{\text {perp }}$ and $D$ is $r=-0.20$.

The data measured later than 12:30 UTC shown in Figs. 5a-d reinforce the impression that the response of the 


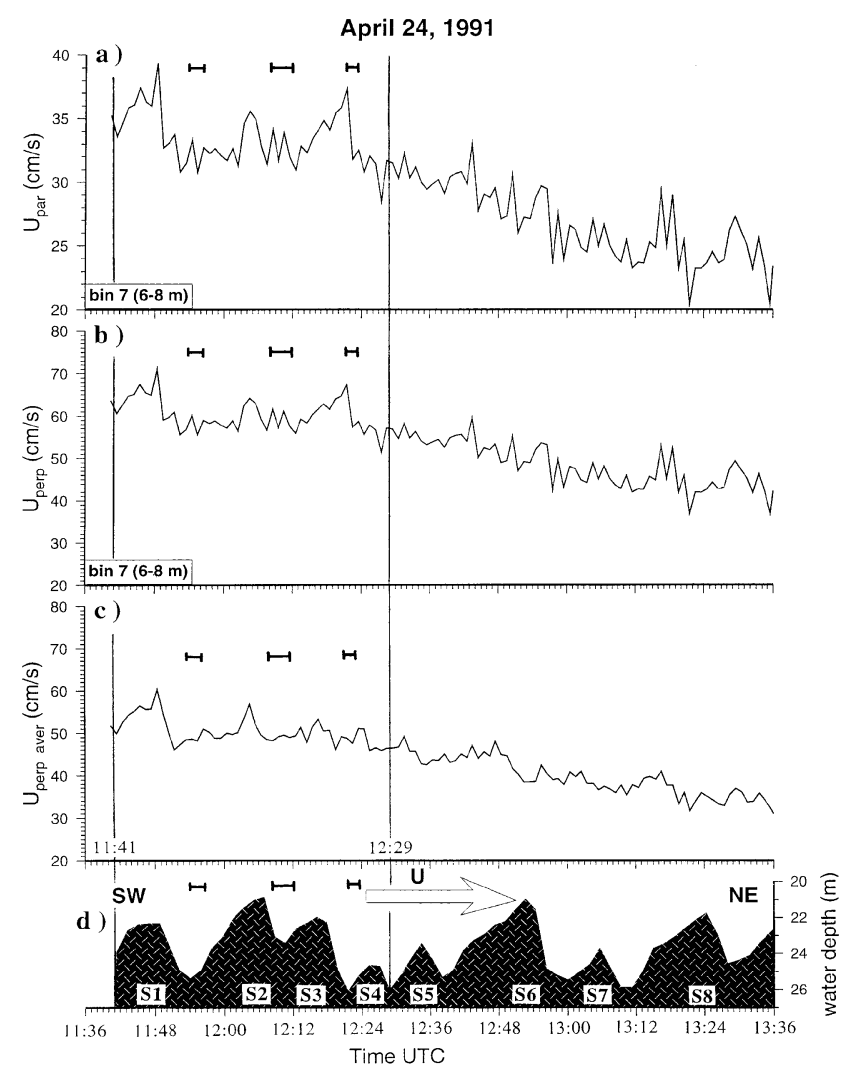

Fig. 5. Time series of Acoustic Doppler Current Profiler (ADCP) measurements between 11:41 UTC and 13:36 UTC on April 24, 1991 of a) parallel $U_{\text {par }}\left(\mathrm{cm} \mathrm{s}^{-1}\right)$ and b) perpendicular current components $U_{\text {perp }}$ $\left(\mathrm{cm} \mathrm{s}^{-1}\right)$ relative to the sand wave crests of bin 7 corresponding to $6-8 \mathrm{~m}$ water depth and c) depth averaged perpendicular current component $U_{\text {perp aver }}\left(\mathrm{cm} \mathrm{s}^{-1}\right)$ relative to the sand wave crests of the current velocity in relation to d) the sea bottom topography. Each tick mark indicates one minute. The water depth profile has been extracted from the bathymetric data shown in Fig. 2a along A-B. Positions of reduced NRCS modulations as a function of wind friction velocity are indicated by short horizontal lines above each graph in Figs. 5a-d at the time interval between 11:41 UTC and 12:29 UTC. The mean current direction is indicated by a white arrow from SW to NW in Fig. 5d.

surface current to the sea bottom topography is not very well marked. During this time mean currents of both the near surface component $U_{\text {perp }}$ and the depth averaged component $U_{\text {perp aver }}$ normal to the sand waves are less than $0.5 \mathrm{~m} \mathrm{~s}^{-1}$.

In summary, these measurements suggest that surface flow changes are detected over some of the sand wave crests, that small sand waves are less likely to produce a significant effect and that there is a greater possibility of observing surface flow perturbations during the strongest tidal flows with a current speed larger than $0.5 \mathrm{~m} \mathrm{~s}^{-1}$. The maximum current velocity is not always observed near the sand wave crests. Van Gastel (1987) showed that advection may be of importance.

Vertical current profiles have been measured from $R V$ Octans using Ott and Elmar current meters at water depths of $1,3,7,12,16,20,22$, and $25 \mathrm{~m}$, respectively. The Ott meters measuring only current speed, the Elmar meters

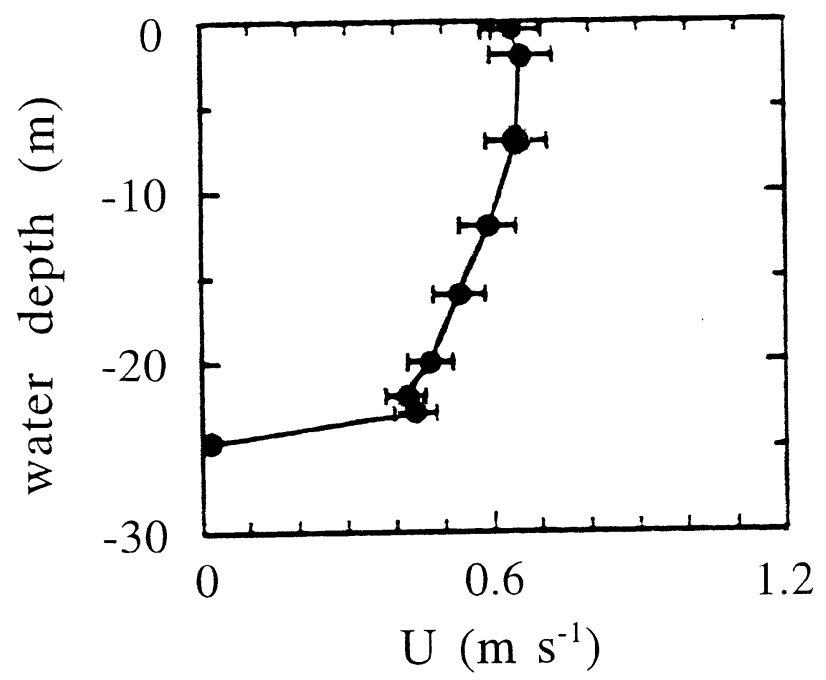

Fig. 6. Vertical current profile measured from board R.V. Octans at 12:09 UTC on April 24, 1991

current direction too. These measurements were made in addition to the ADCP data in order to compare both measuring techniques and to have current velocity profiles of the whole water column available. The position of $R V$ Octans was recorded every minute with a precision of about $2 \mathrm{~m}$ using the radio positioning system Hyperfix. The current velocity was vertically averaged over one minute. Recording of one vertical profile took about $15 \mathrm{~min}$. The absolute accuracy of the current speed is about $10 \%$ and the error in the current direction is about $5^{\circ}$. Fig. 6 shows one of the vertical current profiles that was measured at 12:09 UTC on April 24, 1991. A current velocity of $U=0.65 \mathrm{~m} \mathrm{~s}^{-1}$ was measured at the surface which is consistent with the current data shown in Fig. 5. At a water depth of $24 \mathrm{~m}$ the current velocity was still $0.43 \mathrm{~m} \mathrm{~s}^{-1}$.

\subsection{Water quality data}

A continuous flow monitoring system on board $R V$ Prince Madog recorded water quality parameters from a stream of sea water pumped across a laboratory-based sensor head. The water intake on board the ship was located on the port side at a water depth of $3 \mathrm{~m}$. While drifting it was tried to position the port side of the ship with the water intake upstream in relation to the tidal current direction by brief manuevering of $R V$ Prince Madog. This system measured water temperature, salinity (not shown here), relative uncalibrated data of fluorescence with an excitation wavelength at $440 \mathrm{~nm}$ and beam transmittance using a filter of $665 \mathrm{~nm}$ wavelength at $27.5 \mathrm{~s}$ time intervals. The water temperatures were generally $1{ }^{\circ} \mathrm{C}$ warmer than the ambient sea water temperatures due to warming on the way to the laboratory. The beam transmittance is affected by absorption and scattering and is generally related to suspended particulate matter concentration in the water column. The fluorescence can be used to determine the local chlorophyll 


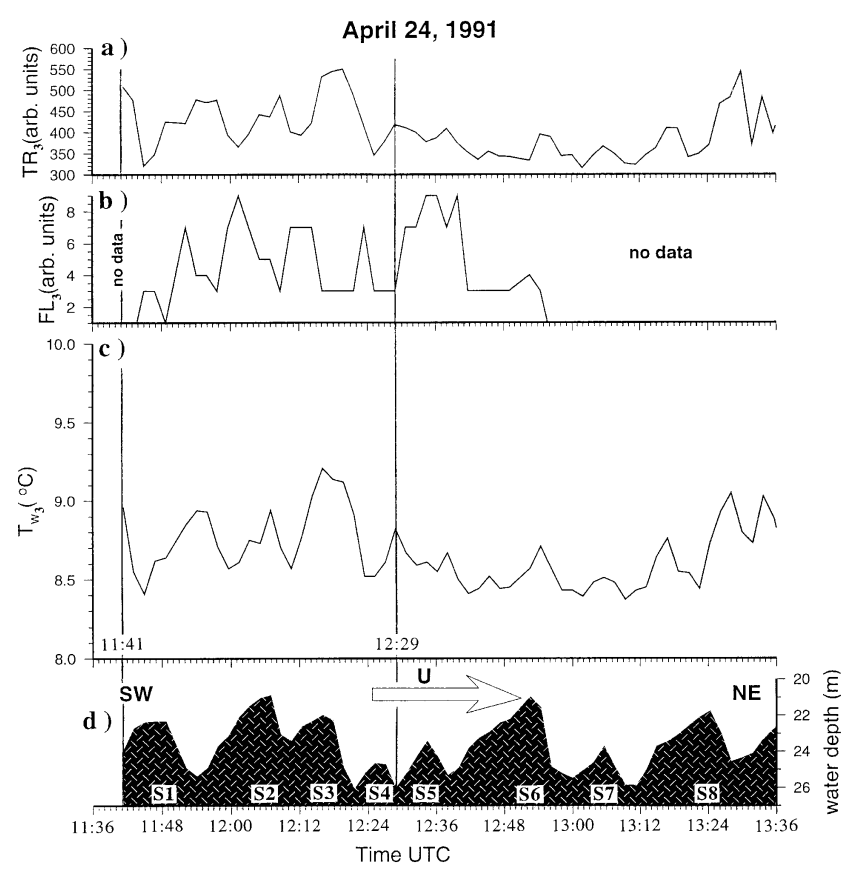

Fig. 7. Time series of a) beam transmittance $T R_{3}$ (arbitrary units), b) fluorescence $F L_{3}$ (arbitrary units), and c) water temperature $T_{\mathrm{W} 3}\left({ }^{\circ} \mathrm{C}\right)$ at 3 $m$ water depth in relation to d) the water depth profile between 11:41 UTC and 13:36 UTC on April 24, 1991. Each tick mark indicates one minute. The water depth profile along A-B has been extracted from the bathymetric data shown in Fig. 2a. The direction of the tidal current $U$ is indicated by a white arrow in Fig. $7 d$.

concentration. Because here we are interested in the associated hydrodynamic behavior of these parameters due to current variations only the uncalibrated data have been used and have not been converted to suspended particulate matter concentration and phytoplankton concentration, respectively.

The quasi-periodic variations in beam transmittance $T R_{3}$, fluorescence $F L_{3}$, and water temperature $T_{\mathrm{w}}$ in relation to the water depth of the drift path A-B of Fig. 2a are shown in Figs. 7a-d. The water depth profile was extracted from the bathymetric map (indicated by A-B) shown in Fig. 2a. Between 11:41 UTC and 12:29 UTC, water temperature and transmittance minimize shortly before the crests of the sand waves and fluorescence maximizing. Cold, turbid, and chlorophyll-rich water from greater water depths below the thermocline arrives prior to the sand wave crests and before the current velocity maximizes (see Figs. $5 \mathrm{a}-\mathrm{c}$ ). The water quality parameters presented in Fig. 7 indicate by their quasi-periodic variations in relation to the sand waves a fairly well developed condition near resonance between the sand waves and the thermocline as considered in section 2 at the time interval between 11:41 UTC and 12:29 UTC. During this time interval the strongest current speeds have been observed (see Figs. 5a-c). It has to be mentioned here again that a frontal boundary (see also section 3.2) passed the ship at about 12:15 UTC (Matthews et al. 1997). The linear correlation coefficient between $T_{\mathrm{w}} 3$ and the water depth $D$ is $r=-0.57$ between 11:41 UTC and 12:29 UTC.
Between 12:30 UTC and 13:36 UTC the tidal current velocity is considerably weaker, equal or less than $0.5 \mathrm{~m} \mathrm{~s}^{-1}$, and the variation in the water quality parameters is somewhat suppressed. However, the maxima in water temperature and beam transmittance also occur at peak tidal current velocities but are not spatially well coinciding with the crests of the sand waves. In summary, the physical conditions of resonance as expressed by equations (9)-(11) in section 2 are almost satisfied in the first part of the time series.

\section{Results}

\subsection{Simulation of NRCS modulation}

In this section simulations of $\left(\Delta \sigma / \sigma_{0}\right)_{\mathrm{tot}},\left(\Delta \sigma / \sigma_{0}\right)_{\mathrm{top}}$, and $\left(\Delta \sigma / \sigma_{0}\right)_{\text {int }}$, respectively, are presented for answering the following question: At what magnitude of stratification using the two-layer model as a first approximation is $\left(\Delta \sigma / \sigma_{0}\right)_{\text {int }}$ as a function of strain rate strong enough at the sea surface to change $\left(\Delta \sigma / \sigma_{0}\right)_{\text {tot }}$ significantly? At first, calculations of $\left(\Delta \sigma / \sigma_{0}\right)_{\mathrm{tot}},\left(\Delta \sigma / \sigma_{0}\right)_{\mathrm{top}}$, and $\left(\Delta \sigma / \sigma_{0}\right)_{\text {int }}$ are performed with the in situ data measured on April 24, 1991 at 18:15 UTC. These data have been used because the CTD measurements were available at water depths between 1-21 $\mathrm{m}$. The calculations correspond to that parts of the sand wave and internal wave which are marked by $\mathrm{C}_{\mathrm{t}}$ and $\mathrm{D}_{\mathrm{t}}$ in Fig. 1b. Figs. 8a-e show the results of the simulations of $\left(\Delta \sigma / \sigma_{0}\right)_{\text {tot }},\left(\Delta \sigma / \sigma_{0}\right)_{\text {int }}$, sinusoidal thermocline $\eta,\left(\Delta \sigma / \sigma_{0}\right)_{\text {top }}$, and $U_{\text {perp }}$, respectively, applying equations (1)-(8). For calculating the strain rate $\partial U_{\text {perp }} / \partial x_{\text {perp }}$ only the real part of the complex expression defined in (5) is considered here. The calculations are carried out for $U_{0}=0.6 \mathrm{~m} \mathrm{~s}^{-1}$, $\Delta U_{\text {perp }}=0.1 \mathrm{~m} \mathrm{~s}^{-1}, L_{\mathrm{SSL}}=50 \mathrm{~m}, L_{\mathrm{GSL}}=450 \mathrm{~m}, \gamma=0.5$, $\mu=0.064 \mathrm{~s}^{-1}, \quad K_{\text {perp }}=0.012566 \mathrm{~m}^{-1}$ with a wavelength $\lambda_{\text {perp }}=500 \mathrm{~m}, \varepsilon=4 \mathrm{~m}, \eta_{0}=\varepsilon / 2=2 \mathrm{~m}, d=5 \mathrm{~m}, D=21 \mathrm{~m}$, $g=9.81 \mathrm{~m} \mathrm{~s}^{-2}, \quad \varrho=1026.415 \mathrm{~kg} \mathrm{~m}^{-3}, \quad$ and $\Delta \varrho=$ $0.075 \mathrm{~kg} \mathrm{~m}^{-3}$. The magnitude of the relaxation rate $\mu$ used for the simulations was based on calculations for L-band radar and in situ measurements of the near surface current velocity and wave energy density above submarine sand waves at a wind speed of $3.8 \mathrm{~m} \mathrm{~s}^{-1}$. For more details the reader is referred to Hennings et al (2001). It is shown in Figs. 8a-b that there is a weak influence of $\left(\Delta \sigma / \sigma_{0}\right)_{\text {int }}$ on $\left(\Delta \sigma / \sigma_{0}\right)_{\text {tot }}$ using the in situ data from April 24, 1991 which is indicated by dashed lines. Simulations of $\left(\Delta \sigma / \sigma_{0}\right)_{\text {tot }}$ and $\left(\Delta \sigma / \sigma_{0}\right)_{\text {int }}$ with the same parameters as described above except for the stratification where $\varrho=1026.5 \mathrm{~kg} \mathrm{~m}^{-3}$ and $\Delta \varrho=1 \mathrm{~kg} \mathrm{~m}^{-3}$ have been used are shown as solid lines in Figs. 8a-b. These simulations demonstrate that at least a density difference of the order of $\Delta \varrho \approx 1 \mathrm{~kg} \mathrm{~m}^{-3}$ is necessary in case of a sinusoidal thermocline to effect the strain rate $\partial U_{\text {perp }} / \partial x_{\text {perp }}$ as well as $\left(\Delta \sigma / \sigma_{0}\right)_{\text {int }}$ and $\left(\Delta \sigma / \sigma_{0}\right)_{\text {tot }}$ considerably. 


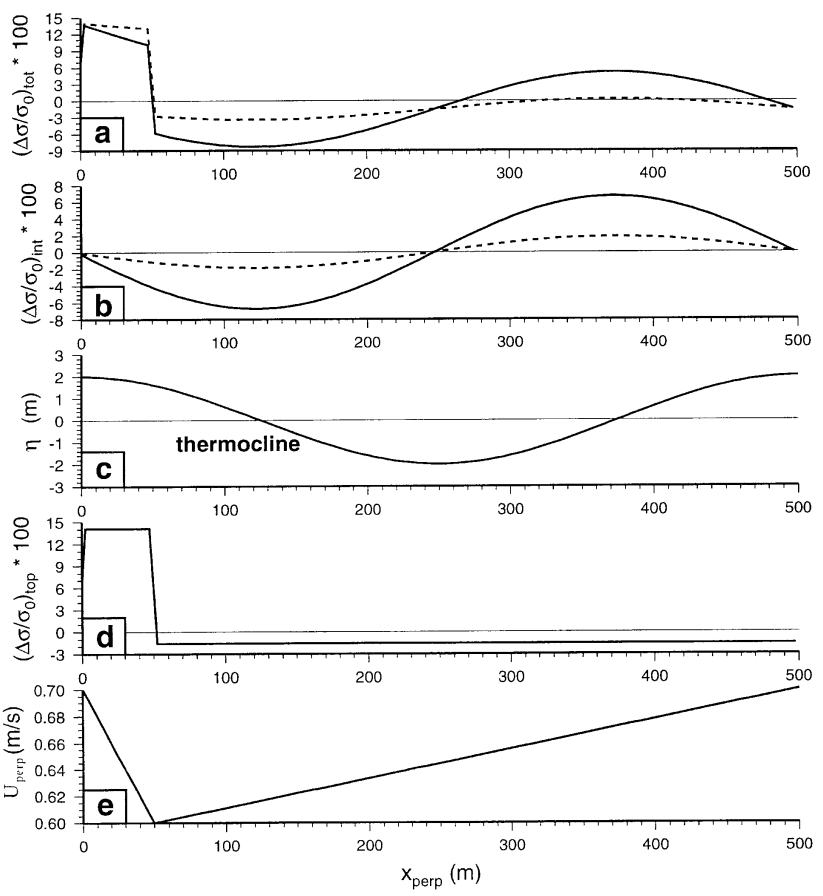

Fig. 8. Simulations of a) $\left(\Delta \sigma / \sigma_{0}\right)_{\text {tot }}$, b) $\left(\Delta \sigma / \sigma_{0}\right)_{\text {int }}$, c) sinusoidal thermocline $\eta$, d) $\left(\Delta \sigma / \sigma_{0}\right)_{\text {top }}$, and e) $U_{\text {perp }}$, respectively, as a function of $x_{\text {perp }}$ applying equations (1)-(8). The calculations correspond to that part of the internal wave which is marked by $C_{\mathrm{t}}$ and $D_{\mathrm{t}}$ in Fig. $1 \mathrm{~b}$ and are carried out for $U_{0}$ $=0.6 \mathrm{~m} \mathrm{~s}^{-1}, \Delta U_{\text {perp }}=0.1 \mathrm{~m} \mathrm{~s}^{-1}, L_{\mathrm{SSL}}=50 \mathrm{~m}, L_{\mathrm{GSL}}=450 \mathrm{~m}, \gamma=0.5, \mu$ $=0.064 \mathrm{~s}^{-1}, K_{\text {perp }}=0.012566 \mathrm{~m}^{-1}$ with a wavelength $\lambda_{\text {perp }}=500 \mathrm{~m}, \varepsilon=4$ $\mathrm{m}, \eta_{0}=\varepsilon / 2=2 \mathrm{~m}, d=5 \mathrm{~m}, D=21 \mathrm{~m}, g=9.81 \mathrm{~m} \mathrm{~s}^{-2}$. Simulations for $\varrho$ $=1026.415 \mathrm{~kg} \mathrm{~m}^{-3}$ and $\Delta \varrho=0.075 \mathrm{~kg} \mathrm{~m}^{-3}$ are indicated by dashed lines in Fig. $8 \mathrm{a}-\mathrm{b}$ and simulations with $\varrho=1026.5 \mathrm{~kg} \mathrm{~m}^{-3}$ and $\Delta \varrho=1 \mathrm{~kg} \mathrm{~m}^{-3}$ are indicated by solid lines in Fig. 8a-b.

\subsection{Investigations of resonance condition using in situ data}

The conditions for resonance are realized (see section 2) if the internal wave number $K_{\text {perp }}$ coincides with the wave number of the submarine sand waves. To investigate the resonance condition, calculations have been carried out using the available in situ data measured on April 24, 1991 at 18:15 UTC and inserting $\mathrm{U}=0.6 \mathrm{~m} \mathrm{~s}^{-1}$, $\partial \varrho / \partial z=0.01875 \mathrm{~kg} \mathrm{~m}^{-4}, \quad \partial^{2} U / \partial z^{2}=2.04 \times 10^{-4} \mathrm{~s}^{-2}, \quad$ and $m=0$ in equations (9)-(11)q. Data of the vertical current profile measured from RV Octans at 12:09 UTC on April 24, 1991 (see Fig. 6) have been used for $U$ and $\partial^{2} U / \partial z^{2}$. Constant values were used for both terms of $\partial \varrho / \partial z$ and $\partial^{2} U / \partial z^{2}$, respectively. The expected precision of $\partial \varrho / \partial z= \pm 10 \%$ and the expected accuracy of $\partial^{2} U / \partial z^{2}= \pm 15 \%$. The resulting internal wave number according to equation (9) is $K_{\text {perp }}=0.01252 \mathrm{~m} \mathrm{~s}^{-1}$ with a wavelength of $\lambda_{\text {perp }}=502 \mathrm{~m}$. This internal wavelength corresponds fairly well with the wavelength of that sand waves crossed by $R V$ Prince Madog between 11:41 UTC and 12:29 UTC (see Fig. 2a).

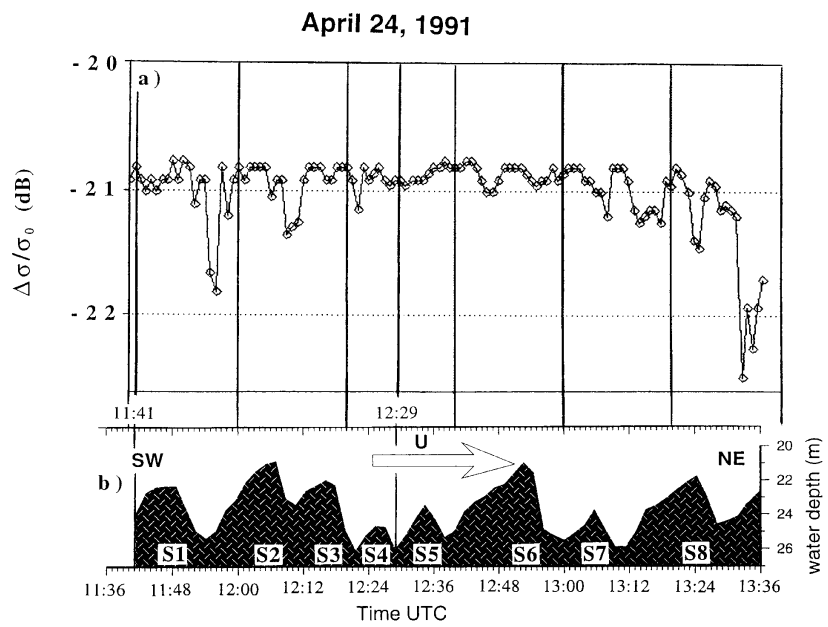

Fig. 9. a) Simulated NRCS modulation $\Delta \sigma / \sigma_{0}$ depending on $\mathrm{u}_{*}$ for C-band radar at $45^{\circ}$ incidence angle as a function of time during the drift between 11:41 UTC and 13:36 UTC on 24 April 1991 in relation to b) the water depth. Each tick mark indicates one minute. The water depth profile A-B has been extracted from the bathymetric data shown in Fig. 2a. The direction of the tidal current $U$ is indicated by a white arrow in Fig. $9 b$.

\subsection{NRCS modulation of wind friction velocity}

Because radar data were not available during the field experiment in April 1991, empirical calculations of the NRCS modulation $\Delta \sigma / \sigma_{0}$ as a function of the wind friction velocity $\mathrm{u}_{*}$ have been carried out. The motivation for this investigation was to find independently variations in $\Delta \sigma / \sigma_{0}$, and/or a relationship with the strain rate resulting by current changes due to the superimposed sand wave/internal wave effects at the water surface. Figs. $9 \mathrm{a}-\mathrm{b}$ show the simulated NRCS modulation $\Delta \sigma / \sigma_{0}$ as a function of time during the drift between 11:41 UTC and 13:36 UTC on 24 April 1991 in relation to the corresponding sea bottom topography.

The wind friction velocity $u_{*}$ was calculated according to the algorithmes published by Liu et al (1979 and Ezraty and Ollitrault (1984). Both models need the following inputs: the wind speed and the height where it is taken, the dry and wet bulb air temperatures and their heights where these parameters were taken, the water surface temperature (bulk temperature), and the air pressure. Dry and wet bulb air temperatures as well as water surface temperatures measured on board $R V$ Prince Madog and the mean wind speed of $\mathrm{U}_{10}=4 \mathrm{~m} \mathrm{~s}^{-1}$ have been used for the calculations. Neutral conditions $\left(-2{ }^{\circ} \mathrm{C}<\Delta T=T_{\text {air }}-T_{\text {water }}<+2{ }^{\circ} \mathrm{C}\right)$ predominated during the measurements.

In the literature models for $\sigma_{0}$ as a function of $\log \left(U_{\mathrm{w}}\right)$ were published (see e.g. Schroeder et al. 1982) with $U_{\mathrm{w}}$ the wind speed. This function can be approximated by a straight line. Here the absolute value of $\sigma_{0}$ is not important but its modulation with the wind speed. This modulation is determined by the inclination of this function, and is reasonably 
known (see e.g. Ulaby et al. 1986) For commonly used C-band radar at $45^{\circ}$ incidence angle a value of 1.5 has been used for the inclination leading to the relationship for the NRCS modulation of:

$$
\frac{\Delta \sigma}{\sigma_{0}}=-21+10 \log \left(\frac{U_{*}}{U_{*_{\mathrm{av}}}}\right)
$$

where $u_{* \mathrm{av}}$ is the average value of the calculated wind friction velocity during the drift between 11:41 UTC and 13:36 UTC on 24 April 1991.

It is shown in Figs. 9a-b that $\Delta \sigma / \sigma_{0}$ is modulated above the sand waves during the drift path. The associated modulation of $\Delta \sigma / \sigma_{0}$ is of the order of $0.5-1 \mathrm{~dB}$, which is low. Typical values of NRCS modulations due to bathymetric undulations such as sand waves are of the order of $\Delta \sigma / \sigma_{0}=1-3 \mathrm{~dB}$ or higher. However, a relationship between the current itself or the total strain rate of the current and $\Delta \sigma / \sigma$ is evident during the time interval between 11:41 UTC and 12:29 UTC. Positions of significantly reduced values of $\Delta \sigma / \sigma_{0}$ have been indicated by horizontal lines in Figs. 5a-d. The first two reduced sharp peaked signatures of $\Delta \sigma / \sigma_{0}$ are coinciding with locations of $U$ where $\pm \partial U / \partial x \approx 0$ (see Fig. 5). The behaviour of the third reduced signature in $\Delta \sigma / \sigma_{0}$ shown in Fig. $9 \mathrm{a}$ at 12:21-12:23 UTC is doubtful due to its association with a frontal boundary which is superimposed on the sand wave/internal wave effect. The less enhanced calculated values of $\Delta \sigma / \sigma_{0}$ have a much broader shape than the sharp peaked reduced ones. But the phase of reduced or enhanced values of $\Delta \sigma / \sigma_{0}$ agree with the total NRCS modulation $\left(\Delta \sigma / \sigma_{0}\right)_{\text {tot }}$ of the schematic visualization presented in Fig. 1 which was based on theoretical considerations discussed in section 2. The corresponding result of the linear correlation coefficient between $\Delta \sigma / \sigma_{0}$ and $U_{\text {perp aver }}$ during the time interval between 11:41 UTC and 12:29 UTC is $r=0.27$. Due to the investigations carried out in this section, it turned out that the existence of a surface roughness-wind stress feedback mechanism cannot be excluded.

\section{Discussion and conclusions}

Effects of superimposed radar imaging mechanisms of sand waves and internal waves near resonance have been discussed in this paper. The analysis of the data gathered in the southern North Sea reflect a special condition which was created together by hydrometeorological, environmental, and water quality data in April 1991. This investigation showed a variety of complex oceanographic processes in the water column as well as their interactions at the oceanatmospheric boundary layer which can disturb radar signatures of submarine sand waves in the coastal zone. The study presented here showed that in a stratified two water layer system, simultaneous reductions in the near-surface water temperature and beam transmittance have been re- corded, whereas fluorescence data are increased above sand waves. The water temperature, beam transmittance and fluorescence variations indicated the development of an internal wave associated with the sand waves as a result of strong flow perturbations induced by the sea bed. Calculations of the NRCS modulation as a function of wind friction velocity showed that this parameter is associated with roughness modulations at the sea surface depending on the strength of the current velocity due to the presence of internal waves and/or submarine sand waves. Simulations of the total NRCS modulation as a function of strain rate showed that at least a density difference between the two water layers of the order of $\Delta \varrho \approx 1 \mathrm{~kg} \mathrm{~m}^{-3}$ should have been developed for a significant contribution of the internal wave effect on April 24, 1991.

Other phenomena like sudden windgusts can instantaneously roughen the sea surface and slicks are coinciding with reduced roughness patterns at the water surface CAlpers. 1995)_Nimmo_Smith et_al_(1999) presented observations of surface effects of bottom-generated turbulence in a tidally influenced and well mixed region of the North Sea. Harden_Jones and Mitson (1982) showed sand waves and bands of acoustical noise measured at the crests of sand waves which can be produced by suspension of bottom sediments. Holligan et al_ (1985) observed areas of surface roughness which were about $5 \mathrm{~m}$ across in smooth water near the internal wave crests. These roughness patterns indicate small-scale turbulent events within the surface mixed layer.

Here it is believed that such kind of mechanisms can be excluded in our study area during the acquisition time of the in situ data.

\section{Acknowledgements}

In situ data have been measured by J.P. Matthews, K. Lwiza and J. Bennel on board RV Prince Madog of School of Ocean Sciences, University of Wales, Menai Bridge, Wales, U.K. All colleagues are acknowledged for providing the data among the participants of the project. We would like to thank also the captains and crews of $R V$ Prince Madog, RV Octans, and RV Christiaan Brunings, STN Atlas Marine Electronics and R. van der Aar for the bathymetric surveys and the processing. Rijkswaterstaat, North Sea directorate and tidal waters division are acknowledged for providing and processing the Ott-Elmar current profiles. The AVHRR image was kindly provided by H. Roozekrans of the Royal Netherlands meteorological institute. We thank G. Haass for technical support. The work has been supported by the European Community (EC) as a part of the first Marine Science and Technology (MAST) programme under contract number MAST-0040-C and as a past of the Energy, Environment and Sustainable Development Programme under contract number EVK-CT-2001-00053. 


\section{References}

Alpers, W., 1985. Theory of radar imaging of internal waves. Nature 314, 245-247.

Alpers, W., 1995. Measurement of mesoscale oceanic and atmospheric phenomena by ERS-1 SAR. Radio Sci. Bull. 275, 14-22.

Alpers, W., Hasselmann, K., 1978. The two-frequency microwave technique for measuring ocean wave spectra from an airplane or satellite. Boundary Layer Meteorol. 13, 215-230.

Alpers, W., Hennings, I., 1984. A theory of the imaging mechanism of underwater bottom topography by real and synthetic aperture radar. J. Geophys. Res. 89, 10529-10546.

Defant, A., 1960. Physical oceanography, (Volume II). Pergamon Press, Oxford, p. 598.

Donato, T.F., Askari, F., Marmorino, G.O., Trump, C.L., Lyzenga, D.R., 1997. Radar imaging of sand waves on the continental shelf east of Cape Hatteras, NC, USA. Contin. Shelf Res. 17, 989-1004.

Ezraty, R., Ollitrault, M., 1984. Estimation de la vitesse de frottement à la surface de la mer à partir de valeurs moyennes de vitesse du vent et des temperatures de l'air et de l'eau. Report. Ifremer, Brest, p. 20.

Harden Jones, F.R., Mitson, R.B., 1982. The movement of noisy sandwaves in the Strait of Dover. J. Cons. Int. Explor. Mer 40, 53-61.

Hennings, I., 1990. Radar imaging of submarine sand waves in tidal channels. J. Geophys. Res. 95, 9713-9721.

Hennings, I., Matthews, J.P., Metzner, M., 1994. Sunglitter radiance and radar cross-section modulations of the sea bed. J. Geophys. Res. 99, $16303-16326$.

Hennings, I., Lurin, B., Didden, N., 2001. Radar imaging mechanism of the sea bed: Results of the C-STAR experiment in 1996 with special emphasis on the relaxation rate of short waves due to current variations. J. Phys. Oceanogr. 31, 1807-1827.

Holliday, D., St-Cyr, G., Woods, N.E., 1987. Comparison of a new radar ocean imaging model with SARSEX internal wave image data. Int. J. Remote Sensing 8, 1423-1430.

Holligan, P.M., Pingree, R.D., Mardell, G.T., 1985. Oceanic solitons, nutrient pulses and phytoplankton growth. Nature 314, 348-350.

Kranenburg, C., 1988a. On internal waves in partially mixed and stratified tidal flows. In: Dronkers, J., Van Leussen, W (Eds.), Physical Processes in Estuaries. Springer, Berlin, pp. 213-238.

Kranenburg, C., 1988. b. Long internal waves and turbulence production in estuarine flows. Estuar. Coastal Shelf Sci. 27, 15-32.

Kropfli, R.A., Ostrovski, L.A., Stanton, T.P., Skirta, E.A., Keane, A.N., Irisov, V., 1999. Relationships between strong internal waves in the coastal zone and their radar and radiometric signatures. J. Geophys. Res. 104, 3133-3148.

Li, X., Morrison, J., Pietrafesa, L., Ochadlick, A., 1999. Analysis of oceanic internal waves from airborne SAR images. J. Coastal Res. 15, 884-891.

Liu, W.T., Katsaros, K.B., Businger, J.A., 1979. Bulk parameterization of air-sea exchanges of heat and water vapor including the molecular constrains at the interface. J. Atmos. Sci. 36, 1722-1735.

Matthews, J.P., Wismann, V.R., Lwiza, K., Romeiser, R., Hennings, I., De Loor, G.P., 1997. The observation of the surface roughness characteristics of the Rhine plume frontal boundaries by simultaneous airborne thematic mapper and multifrequency helicopter-borne radar scatterometer. Int. J. Remote Sensing 18, 2021-2033.
Munk, W., 1981. Internal waves and small-scale processes. In: Warren, B.A., Wunsch, C (Eds.), Evolution of physical oceanography. MIT Press, Cambridge, Massachusetts, pp. 264-291.

New, A.L., Dyer, K.R., 1988. Internal waves and mixing in stratified estuarine flows. In: Dronkers, J., Van Leussen, W (Eds.), Physical Processes in Estuaries. Springer, Berlin, pp. 239-254.

Nimmo Smith, W.A.M., Thorpe, S.A., Graham, A., 1999. Surface effects of bottom-generated turbulence in a shallow tidal sea. Nature 400, 251-254.

Phillips, O.M., 1977. The dynamics of the upper ocean. Cambridge University Press, New York.

Pietrzak, J.D., Kranenburg, C., Abraham, G., 1990. Resonant internal waves in fluid flow. Nature 344, 844-847.

Romeiser, R., Alpers, W., 1997. An improved composite surface model for the radar backscattering cross section of the ocean surface. 2. Model response to surface roughness variations and the radar imaging of underwater bottom topography. J. Geophys. Res. 102, 25251-25267.

Romeiser, R., Ufermann, S., Solte, S., 1999. Energy transfer between hydrodynamically modulated long and short ocean waves by interaction with the wind field. Proc. IGARSS'99 Symposium, Hamburg, Germany, Institute of Electrical and Electronics Engineers. pp. $965-967$.

Schroeder, L.C., Boggs, D.H., Dome, G., Halberstam, I.M., Jones, W.L., Pierson, W.J., Wentz, J., 1982. The relationship between wind vector and normalized radar cross section used to derive Seasat-A satellite scatterometer winds. J. Geophys. Res. 87, 3318-3336.

Shuchman, R.A., Lyzenga, D.R., Meadows, G.A., 1985. Synthetic aperture radar imaging of ocean-bottom topography via tidal-currents interactions: theory and observations. Int. J. Remote Sensing 6, $1179-1200$.

Stride, A.H., Tucker, M.J., 1960. Internal waves and waves of sand. Nature $188,933$.

Thompson, D.R., Gasparovic, R.F., 1986. Intensity modulation in SAR images of internal waves. Nature 320, 345-348.

Ulaby, F.T., Moore, R.K., Fung, A.K., 1986. Microwave Remote Sensing: Active and Passive (in three volumes), Volume III, From Theory to Applications, Artech House, Inc., Dedham.

Van Alphen, J.S.L.J., De Ruijter, W.P.M., Borst, J.C., 1988. Outflow and three-dimensional spreading of Rhine river water in the Netherlands coastal zone. In: Dronkers, J., Van Leussen, W (Eds.), Physical Processes in Estuaries. Springer, Berlin, pp. 70-92.

Van Gastel, K., 1987. Velocity profiles of tidal currents over sand waves. Neth. J. Sea Res. 21, 159-170.

Vogelzang, J., 1993. Mapping of sea bottom topography in a multi-sensor approach. In: Weydert, M., Fragakis, C (Eds.), MAST days and EUROMAR market, 15-17 March 1993, Brussels, Belgium, Project Reports, Vol. 2. Office for Official Publications of the European Communities, Luxembourg, pp. 534-549.

Vogelzang, J., 1997. Mapping submarine sandwaves with multi-band imaging radar 1 . Model development and sensitivity analysis. J. Geophys. Res. 102, 1163-1181. 